\title{
Preliminary Study on the Characteristics of the Traditional Village Space in Chongqing Tujia Village in Qianjiang
}

\author{
Xiaomeng Lou \\ School of Architecture and Urban Planning \\ Southwest University for Nationalities \\ Chengdu, China
}

\author{
Ying Meng \\ School of Architecture and Urban Planning \\ Southwest University for Nationalities \\ Chengdu, China \\ Jin Yang \\ School of Architecture and Urban Planning \\ Southwest University for Nationalities \\ Chengdu, China
}

\author{
Qian Wang \\ Southwest University for Nationalities \\ school of architecture and Urban Planning \\ Chengdu, China \\ Kangcai Nie \\ School of Architecture and Urban Planning \\ Southwest University for Nationalities \\ Chengdu, China
}

\begin{abstract}
Tujia is a nation with a long history in China. Tujia traditional village in Chongqing pays more attention to "harmony of man with nature" in the landscape pattern of the site, with seven elements like " Mountains, forests, fields, roads, water, villages", and in the courtyard space, there are some space adapting to terrain like stilts, the architecture like the word "-", "L", "U" surrounding a typical courtyard of Tujia architecture. In landscape space, clustering round the beauty of the natural beauty of the canyon, the village gate, boasting, stilts and some national characteristic architectures had constituted the important scenery factor, and mountains, roads, water systems, orchards, farmland has constitute the free and unit landmark landscape of Tujia. Because of the unique mountain canyon topography, Tujia villages has been built along the Banjia-stresm upstream, and become a multi group band distributed characteristics. Tujia village building consists by traditional houses like stilts, and there are central room with most characteristic, and the fire spread before bedroom, and wing-room with stilts, and derived-rooms which can satisfy the need of human. The rapid economic development bring an international trend had made it imminent to collect, arrange, protect and inherit the nation building culture. Tujia traditional village is a kind of unique cultural resources, study on the deep national cultural heritage in Tujia Qianjiang Chongqing can transmit the spatial characteristics in Fengshui location, courtyard space, landscape space and architectural space. Recording them by pictures and texts can cause important practical significance in the arrangement and development of national architectural culture, protect ion of national culture and develop characteristic regional architecture. I would like to this article, to arouse attention from more people, protect and
\end{abstract}

This project is supported by the innovation project of Southwest University for Nationalities, project number: CX2015SZ011.

Ying Meng: Correspondence author promote the construction of the Tujia villages.

Keywords-Tujia village; traditional country; space characteristic; courtyard; landscape; architecture

\section{INTRODUCTION}

"Plate clip creek thirteen walled" is one of the first batch of ethnic minority villages Chinese which named by national council of state. There are a lot deep culture in Tujia architecture, agriculture and nationality culture, combined the source with nature, population and canyon. Not only did the first Tujia ecological museum in china, but also the most beautiful and the biggest Tujia original ecological tourism zone.

In recent years, with the rapid development of urban construction, it is gradually apathetic to the regional characteristics of architecture. Special geographical conditions and climatic conditions required the construction development to respect for local, national characteristics. Through field investigation of Tujia thirteen villages in Qianjiang Chongqing, combined literature review to comprehensive analysis Fengshui location, courtyard space, landscape space and architectural space of the Tujia traditional countries in Qianjiang Chongqing. And I hope to give a power to contribute to the arrangement and development of national architectural culture and the protection of national culture. 


\section{RESEARCH ON CHARACTERISTICS OF TUJIA VILLAGE SPACE}

Zhouliang(2005) had studied the content of Fengshui location, feature space and art, and he had introduced the most characteristic of Tujia flavor in the south-east of Chongqing: central room, the fire spread before bedroom, located at the intersection of the main wing-room and the "angle" house, and the attic, corridor and dam. In the base of the analysis of construction idea of the traditional dwelling houses in Tujia village, Feng Weibo (2014) put out the spatial characteristics of settlement should contain diversified characteristics of the flat type system of dwelling houses, the features alongside mountains and rivers, the features of cultivated land first, the form feature of group- order- extension structure. There are two types of settlement space form, which are free scattered point layout and focus group. He had analyzed the cause of settlement space, considered that the spatial characteristics of the traditional dwelling houses in Tujia village in the southeast of Chongqing was changed by the special terrain condition funded the Chinese traditional courtyard houses.

It is the one kind of characteristic above the traditional village researches like architectural space and landscape space, or study on the overall characteristics of village space. There are not a scholar specialized to collate and induct from global to local in the spatial characteristics of Tujia traditional villages. So, it is necessary to collate and induct the spatial characteristics of Tujia traditional villages, and it had some research value.

\section{THE SPATIAl CHARACTERISTICS OF TUJIA TRADITIONAL VILLAGES IN QIANJIANG CHONGQING}

\section{A. The Spatial Characteristics of Landscape Space}

1) Canyon landscape features with native natural beauty: Tujia village landscape space primary grow based on the regional morphology and blend with nature. Hundreds years reconstruction and construction by Tujia can also reflect the nature of the local landscape environment. It has its own characteristic, and live in symbiosis and harmony with tujia and the landscape space is natural and protosomatic. On the overall spatial layout of the village, the villages is made up a group upstream the Banjia-stream. From the Xuetanwan near the new street in Houba to the cradle of Banjia-stream in the foot of Jigong mountain, combined a group with zonal distribution to 13 Tujia villages original. Tujia live there along the river and together with others, formed a typical representative of the Tujia residential community "Fig. 1".

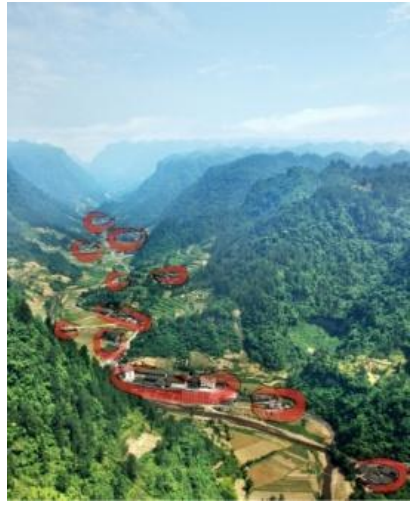

Fig. 1. multi group band distributed characteristics

2) The symbolic landscape elements with national characteristics: Village gate, boasting, stilts are the most national characteristics of Tujia village, and also the symbolic landscape elements of tujia "Fig. 2" the free and unit landmark landscape like mountains, roads, water systems, orchards, farmland are the main landscape elements of Tujia village, that rendering the landscape of Tujia is more national characteristics and highly identifiable.
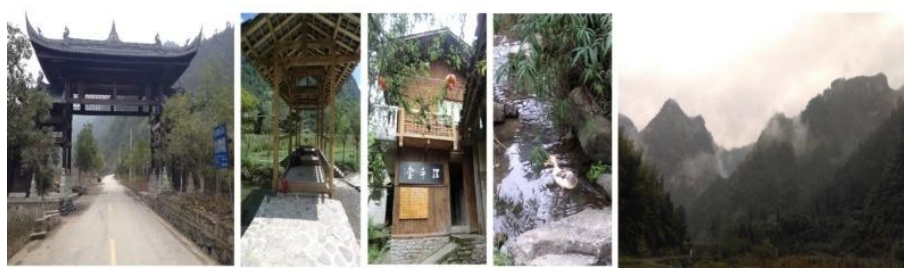

Fig. 2. the village gate, boasting, Waving Hall water mountain

3) Landscape pattern characteristics of "harmony of man with nature" and" seven elements constitute together" : Many Tujia villages built along the stream, and keep some distance among the stream; so between the stream and village, there were many farmlands to avoid flood disaster and the soil scoured by the flood will be fertile and more suitable for growth of crops. Channels of communication with the outside world had been built across the stream, so that the stream became the natural moat "Fig. 3". The cause of the pattern is that in the case of low technical level, people still have no power to compete with the natural environment, and choose the right place to live according to the characteristics of production. In a sense, the low objective technical level caused the sense of "conform to the world environment" of "harmony of man with nature" in a manner.

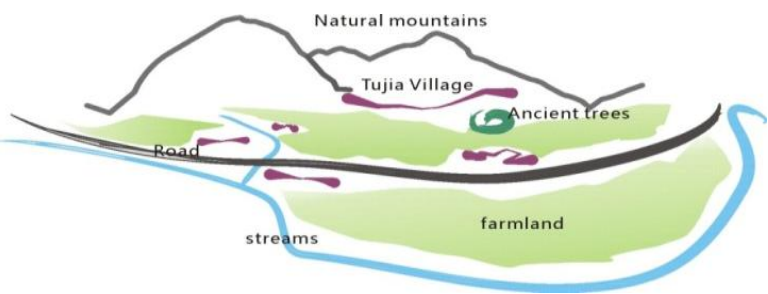

Fig. 3. The site selection sketch map of Tujia village 
There were distributed 13 Tujia villages upstream the Banjia-stream; and Tujia live there along the river and together with others, formed a typical representative of the Tujia residential community. Each village alongside mountains and rivers, with its unique shape are coupled tightly. The site selection of Tujia architecture reflect the traditional village characteristic selection with seven elements like "Mountains, forests, fields, roads, water, village".

\section{B. The Spatial Characteristics of Courtyard Space}

1) The architecture like the word" - ", " $L ", ~ " U$ " surrounding a typical courtyard of Tujia architecture: The house like the word "- " are main-room or wing-rooms lined up, and always three rooms in bright three and dark five and five rooms in bright five and dark nine, seven is the most and we had not found nine. The house like the word "L" are combined by one main-room and one wing. The house like the word " $U$ " are in the base of "L" and added a wing-room, that is one main-room and two wing-rooms, also called "three fusion water" "Fig. 4".
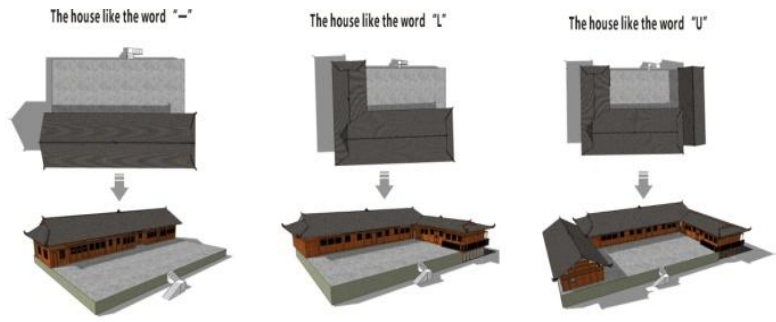

Fig. 4. Courtyard combination characteristic

2) Adapted to terrain and courtyard space characterized by stilts: The stilt is an enclosed form developed by the mountain and combined by the main courtyard with bottom overhead, and is the derivative of dry column type courtyard. This courtyard spaces are always near the slope and ridge, Make a column on the land and use the way of stilt to combine with the land. The stilt is more adaptable to the mountain. Interior space is also very unique, and you can find that the half on the ground and half on the floor to form unique space. Not only would make the courtyard get good beauty, but also can solve the limit of land space, that rendering the space environment more unique "Fig. 5" / "Fig. 6".

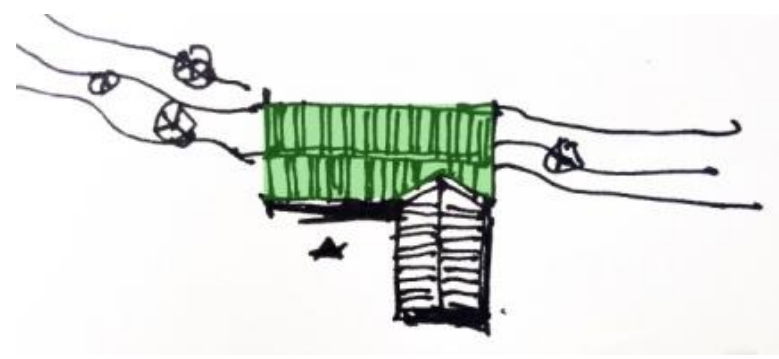

Fig. 5. The ichnography of typical courtyard houses of stilts

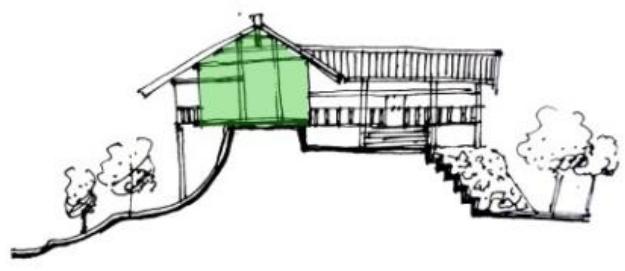

Fig. 6. The elevation of typical courtyard houses of stilts

\section{Architectural Spatial Characteristics}

Architecture of Tujia village were constituted by traditional stilts, and there are central room with most characteristic, and the fire spread before bedroom, and wingroom with stilts, and wing-room with stilts, and derived-rooms everywhere.

1) Great attention has been paid to the central room space: The central room is the centre of the Tujia house with worship shrine in the back of the wall, and its functions of central room are worship of ancestors, greet guests,wedding and funerals. The furnishings in the central are only the facilities of worshipping without other items, so that can guarantee the central room seriousness and nobility. In traditional Tujia house, there is no door in the central room or even there is a door they never closed. The design of Tujia central room is respecting the etiquette, meeting their psychological needs and inheritance of Chinese traditional religious culture.

2) Peculiar fire spread: Fire spread, is an interior architecture which have a fiery pit on the ground. The central room left and right sides are bed-rooms, and the half of the front right bedroom is kitchen and there is a fiery pit on the ground, so this room is called fire spread "Fig. 7". The fire spread is the important space for Tujia daily activities like cooking, eating, warm hospitality, leisure, consultation, chat and other activities.

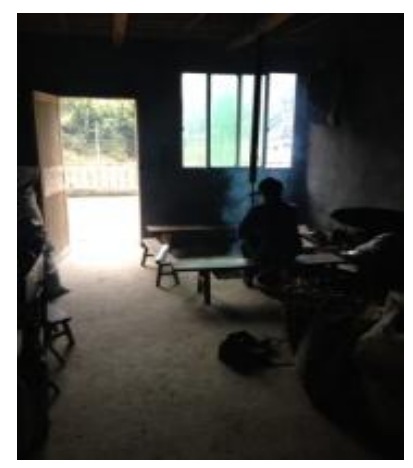

Fig. 7. Fire spread

3) Representative wing-room with stilts: Because of the mountain and land, they always build central room on the only few flat ground which was flatted by human-being (some central rooms are not all on the ground, and parts of them are stilts). However, because the wing-rooms are perpendicular to 
the central room, and there are no place to them to become stilts. This kind of house becomes the form with the mountain in the back and the water in the front. These kinds of wingrooms are the most Tujia ethnic characteristics and taste, and the most representative of the typical building.

4) Derived-rooms everywhere: The derived-room, which means they are built to satisfy the need of daily life like adding, sticking, putting, building, expanding to assist "Fig. 8 ". These kinds of rooms have no limits, no forms, wide use like storage room, beasts room, restroom, toilet. They are free, flexible and built by the clever Tujia people in the light of its general trend and adapting to terrain. As long as it can be convenient to their life, the forms of derived-rooms have more randomness and flexibility. It is an indispensable part for living function, and also gives a variety of changes to the overall space of the residence. It is an important part of Tujia house features.

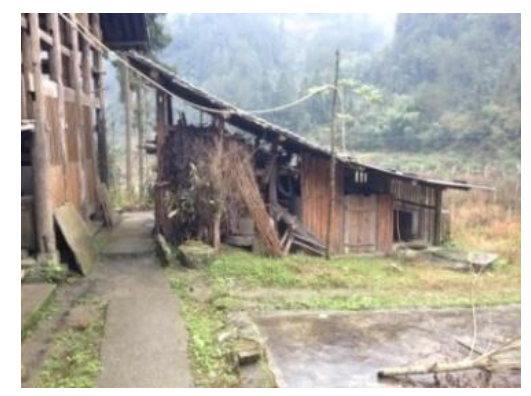

Fig. 8. Derived-room

\section{CONCLUSION}

The rapid economic development bring an international trend had made it imminent to collect, arrange, protect and inherit the nation building culture. Tujia traditional village is a kind of unique cultural resources, study on the deep national cultural heritage in Tujia Qianjiang Chongqing, which can transmit the spatial characteristics in Fengshui location, courtyard space, landscape space and architectural space, and recording them by pictures and texts can cause important practical significance in the arrangement and development of national architectural culture, protect ion of national culture and developing characteristic regional architecture. I would like to this article, to arouse more people to join the attention, protect and promote the construction of the Tujia villages.

\section{REFERENCES}

[1] Zhou Liang. Study on Tujia folk houses in the southeast Chongqing and traditional building technique [D] Chongqing University 2005.

[2] Shu Bo, Zhang Meng. Rooted in the regional culture and continued the traditional settlement space characteristics - take the planning and design of the new village of Shiniu Wenchuan county as the example [J] <Planner> symposium, 2011,00:161-165.

[3] Shan Lan, Xu Xinya. The features and protection of ethnic village landscape space in north Guangxi $[\mathrm{J}]$ construction of small towns, 2011, 07.
[4] Feng Weibo. Research on the spatial characteristics mountain traditional dwelling in Tujia village in the southeast Chongqing [J] Huazhong Architecture, 2014, 01.

[5] Jiang Weibo. Research on the spatial form of Miao village in southeast area of Guizhou [D] Central Academy Of Fine Arts, 2013

[6] Tian Lu. The study of ZhangJiajie Tujia mountain fastness interior space form [D] Central South University of Forestry and Technology, 2013

[7] Fang Zhendong. Research on the traditional village landscape in Enshi Tujia village [D] Nanjing Agricultural University, 2012

[8] Shan Juan. The application of Tujia culture in landscape design in southwest Hubei [D] Northwest Agriculture and Forestry University, 2013

[9] Xiao Xiangdong. Research on the layout and space of ethnic architecture of Xiangxi's traditional dwellings [D] Central South University of Forestry and Technology, 2004

[10] Yang Huimei. The spatial layout features of traditional Dong Village and its modern revelation [J] Journal of Guizhou University (art), 2010, 02:26-29.

[11] Zhou Shiya. Research on the ethnic tourism village spatial form which based on the perception of tourists and residents [D] Huazhong Agricultural University, 2014

[12] Pan Wei. Research on the features of carpentry work and folk construction technology in Tujia village southwest Hubei [D] Huazhong University of Science and Technology, 2012. 